\title{
Male Breast Cancer: 20-Year Survival Data for Post-Mastectomy Radiotherapy
}

\author{
Holm Eggemann ${ }^{a}$ Atanas Ignatov ${ }^{a}$ Roland Stabenow ${ }^{b}$ Gunter von Minckwitz ${ }^{c}$ \\ Friedrich Wilhelm Röhld ${ }^{d}$ Peter Hass ${ }^{\mathrm{e}}$ Serban-Dan Costa ${ }^{\mathrm{a}}$ \\ aUniversity Women's Clinic, Otto von Guericke University, Magdeburg, \\ ${ }^{b}$ Common Registry of Cancer, Berlin, \\ 'German Breast Group, Neu-Isenburg, \\ IInstitute of Biometrics and Medical Informatics, \\ eDepartment of Radiotherapy, Otto von Guericke University, Magdeburg, Germany
}

\section{Keywords}

Male breast cancer - Adjuvant radiotherapy .

Adjuvant Therapy · Overall survival

\section{Summary}

Background: The goal of this population-based study was to determine the impact of post-mastectomy radiation therapy on long-term overall survival (OS) of male patients with breast cancer. Patients and Methods: We investigated 20-year OS rates of 664 patients diagnosed with primary stage I-III breast cancer in former East Germany between 1970 and 1989. Patients had a radical mastectomy with axillary lymph node dissection without systemic adjuvant therapy. Results: Median follow-up time was 26.2 years (range $19-38$ years). $52.4 \%$ of the patients had post-mastectomy radiotherapy. Radiotherapy showed different effects in each stage group after 20 years. Whereas there was an OS trend for radiotherapy to harm patients with stage I disease (hazard ratio (HR) 1.45; 95\% confidence interval (Cl) 0.98-2.15; $\mathrm{p}=0.065)$, radiotherapy showed no benefit in patients with stage II disease (HR 0.82;95\% Cl 0.62-1.1; $\mathrm{p}=0.15$ ). There was a significant survival benefit for patients with stage III disease receiving radiotherapy (HR 0.60; $95 \% \mathrm{Cl}$ 0.41-0.88; $p=0.008$ ). Conclusion: Post-mastectomy radiotherapy is associated with longer OS in male patients with stage III breast cancer. Male breast cancer patients at stages I and II do not seem to benefit from radiotherapy, but obsolete irradiation techniques might explain adverse long-term effects in earlier stages.

\section{Schlüsselwörter \\ Männliches Mammakarzinom · Adjuvante Bestrahlung · Adjuvante Therapie · Gesamtüberleben}

\section{Zusammenfassung}

Hintergrund: Ziel dieser retrospektiven Studie war es, den Einfluss der postoperativen Bestrahlung bei männlichen Patienten mit einem Mammakarzinom auf das Langzeitgesamtüberleben zu untersuchen. Patienten und Methoden: Es wurden 664 Patienten in dem Zeitraum von 1970-1989 und einem Stadium I-III aus dem Tumorregister der früheren DDR ausgewertet. Die Patienten erhielten eine radikale Mastektomie mit oder ohne postoperative Bestrahlung. Keiner der Patienten erhielt eine adjuvante systemische Therapie. Ergebnisse: Die mediane Nachbeobachtungszeit betrug 26,2 Jahre (Spanne 19-32 Jahre). 52,4\% der Patienten wurden postoperativ bestrahlt. Die postoperative Bestrahlung zeigte in Abhängigkeit des Erkrankungsstadiums unterschiedliche Effekte auf das Gesamtüberleben nach 20 Jahren. Während die Patienten mit Bestrahlung im Stadium I, die jünger als 75 Jahre waren, ein tendenziell kürzeres Gesamtüberleben hatten (Hazard Ratio (HR) 1,45; 95\%-Konfidenzintervall (KI) 0,98-2,15; $p=0,065$ ), war bei Patienten im Erkrankungsstadium II kein signifikanter Unterschied festzustellen (HR 0,82; 95\%-KI 0,62-1,1; $p=0,15$ ). Patienten im Stadium III hingegen profitierten erheblich von der postoperativen Bestrahlung (HR 0,60; 95\%-KI 0,41-0,88; $p=0,008)$. Schlussfolgerung: Die postoperative Bestrahlung führt zu einem signifikant besseren Langzeitgesamtüberleben für männliche Patienten mit Mammakarzinom im Stadium III. Patienten in den Stadien I und II scheinen von der postoperativen Bestrahlung nicht zu profitieren. Die mit der damaligen Technik der Bestrahlung assoziierte Morbidität könnte hierfür die Erklärung sein.

\section{KARGER \\ Fax +497614520714 \\ Information@Karger.com}

www.karger.com (c) 2013 S. Karger GmbH, Freiburg

$1661-3791 / 13 / 0084-0270 \$ 38.00 / 0$

Accessible online at:

www.karger.com/brc
Dr. med. Holm Eggemann

Universitäts-Frauenklinik

Otto-von-Guericke-Universität

Gerhart-Hauptmann Str. 35, 39108 Magdeburg, Germany

Holm.Eggemann@med.ovgu.de 


\section{Introduction}

Male breast cancer is a rare disease with a prevalence of $1: 100,000$ in the European population, comprising less than $1 \%$ of all documented breast cancer cases [1]. However, the overall incidence of male breast cancer has been rising continuously, climbing by $26 \%$ over the past 25 years [2]. Advanced age predisposes for male breast cancer, but it has been reported in male patients of all ages (5-93 years) [3]. While its etiology remains unclear, hormone levels, testicular abnormalities, congenital inguinal hernia, orchiectomy, orchitis, and infertility have been discussed as risk factors $[4,5]$. Since it is a potentially fatal disease, there is a definite need to establish well-defined therapeutic regimens. Due to its rarity, however, it is very difficult to conduct prospective randomized trials, hence an analysis of the data of national cancer registries provides an opportunity to gain insight into the disease course for male breast cancer. Therefore, treatment concepts rely on data of female breast cancer $[2,6,7]$, but their applicability in men remains unclear. For many decades, local therapy of male breast cancer has consisted of mastectomy with axillary lymph node dissection. Evidence for the longterm efficacy of post-mastectomy radiotherapy (RT) for male patients is scarce and is mostly extrapolated from studies on female breast cancer [8-11]. Post-mastectomy RT in female breast cancer patients, applied to the chest wall, significantly decreases the likelihood of local tumor recurrence and improves the overall survival (OS) rates only in high-risk patients [12]. While it has been shown that adjuvant RT reduces tumor recurrence rates for male breast cancer as well, no comparable benefit concerning the OS rates has been observed as of yet [10]. Hence, there is insufficient evidence to consider individualized post-mastectomy RT in men, and its recommendation as a routine standard procedure is still under discussion $[13,14]$. The present study focused on the analysis of all documented male breast cancer cases diagnosed between 1970 and 1989, followed up until the year 2007 and documented in the population-based tumor registry of former East Germany. The aim of our study was to determine the influence of post-mastectomy RT on the 10- and 20-year OS rate of this large study population. Since patients did not received any systemic therapy, our analysis provides unique evidence for the impact of adjuvant RT alone.

\section{Patients and Methods}

\section{Study Population}

For all cases, patient and disease data on male breast cancer were obtained from the national cancer registry of former East Germany. This database was established in 1953 and documented around 1.8 million cases of patients with various malignant and benign tumors until the year 1990, when East Germany had a total population of 17 million people. It is one of the largest population-based tumor registries worldwide [15]. Documented patient data included information about diagnosis, date of diagnosis, patient's age at diagnosis, tumor stage (denoted as I-IV), type of the administered therapy, and, if available, the date of death. The database neither included the 'TNM Classification of Malignant Tumours' (TNM: tumor, nodes, metastasis), nor information on co-morbidities.

For analysis, we used data on all 924 male patients with primary breast cancer diagnosed between the years 1970 and 1989. For tumor staging, the UICC criteria were used (//old.uicc.org/index). Stages were defined as follows (1978): Stage I: T1, N0 and N1a (non-palpable or palpable but non-suspect axillary lymph nodes); Stage II: T0-1 and N1b or T2 N0-1; Stage III: T3-4, all N, or all T and N2-3; Stage IV: all T or all N and M1. Exclusion criteria were unknown stage of disease, stage IV cancer, adjuvant chemotherapy recipients, or hormonal therapy recipients. The resulting population size comprised 664 eligible cases for analysis. All of these patients had been subjected to radical mastectomy and axillary lymph node dissection. Post-surgical RT was performed according to the respective standard daily practice. Megavoltage irradiation with Cobalt 60 without modern planning devices was the predominant method used during that time. Radiation of regional lymph nodes was undertaken in the case of positive axillary lymph nodes.

Follow-up data were collected until 2007 for the last patient. OS was the primary endpoint, defined as the time between date of registration and date of death or date of last patient data entry in the tumor registry. We calculated the 10- and 20-year OS rates. In order to minimize a possible influence of advanced age and comorbidities on the effect of postsurgical RT and OS, we performed a separate analysis on a subgroup of 487 patients aged $<75$ years at the time of diagnosis.

\section{Statistical Analysis}

All statistical calculations were performed using the software package PASW Statistics 18.0 (SPSS, Chicago, IL, USA). The 10- and 20-year OS rates were calculated using the Kaplan-Meier method, and comparisons between the patient groups were made using two-sided log-rank tests. Statistical relationships between the OS and RT with respect to baseline factors were evaluated with $\chi^{2}$ - and Fisher's exact tests. Univariate and multivariate Cox proportional hazard regression analysis including age, stage, and year of diagnosis was performed to adjust treatment effects for potential biases.

\section{Results}

\section{Patient Characteristics}

The mean patient age of the total study population was 65.5 years (range 20-95 years), and the median follow-up time interval was 314 months (standard deviation $(\mathrm{SD}) \pm 71.5$ months, range 299-461 months). Table 1 presents the distribution of the study population: $52.4 \%(348 / 664)$ of patients had received adjuvant RT during therapy. Most patients had stage II disease $(\mathrm{n}=288,43.4 \%)$. Concerning age, stage I patients were equally distributed in the 2 groups - surgery alone versus surgery plus RT. Patients were older in advanced tumor stages II and III in the surgery alone group than in the surgery plus RT group (stage II patients 68.6 vs. 63.4 years; $p=0.001$, stage III: 72.8 vs. 64.3 years; $p<0.001$, respectively).

To exclude potential bias of fatal co-morbidities more prevalent in elderly patients, a subgroup analysis of patients $<75$ years was performed (table 1$) .487$ patients $(73 \%)$ were younger than 75 years with a mean age of 60.3 years and a mean follow-up interval of 302 months (SD \pm 69.7 months, range $229-461$ months). $57.3 \%$ of these patients (279/487) had 


\begin{tabular}{|c|c|c|c|}
\hline & Surgery & Surgery + RT & $\mathrm{p}$ value \\
\hline $\begin{array}{l}\text { All patients, } \mathrm{n} \text {, } \\
\text { Mean age; years } \pm \mathrm{SD}\end{array}$ & $\begin{array}{c}316(47.6 \%) \\
67.5 \pm 13 \cdot 7\end{array}$ & $\begin{array}{r}348(52.4 \%) \\
63.7 \pm 11.7\end{array}$ & $<0.001$ \\
\hline $\begin{array}{l}\text { Stage I, } \mathrm{n} \\
\text { Stage I, mean age; years } \pm \mathrm{SD} \\
\text { Stage II, } \mathrm{n} \\
\text { Stage II, mean age; years } \pm \mathrm{SD} \\
\text { Stage III, } \mathrm{n} \\
\text { Stage III, mean age; years } \pm \mathrm{SD}\end{array}$ & $\begin{array}{c}138(60.0 \%) \\
64.4 \pm 13.9 \\
119(41.3 \%) \\
68.6 \pm 14.3 \\
59(40.4 \%) \\
72.8 \pm 9.0\end{array}$ & $\begin{array}{r}92(40.0 \%) \\
63.6 \pm 12.2 \\
169(58.7 \%) \\
63.4 \pm 11.8 \\
87(59.6 \%) \\
64.3 \pm 11.2\end{array}$ & $\begin{array}{l}0.67 \\
0.001 \\
<0.001\end{array}$ \\
\hline $\begin{array}{c}\text { Patients }<75 \text { years, } n=487 \\
\text { Mean age, years } \pm S D\end{array}$ & $\begin{array}{r}208(42.7 \%) \\
60.8 \pm 11.7\end{array}$ & $\begin{array}{r}279(57.3 \%) \\
60.0 \pm 10.0\end{array}$ & 0.484 \\
\hline $\begin{array}{l}\text { Stage I, } \mathrm{n} \\
\text { Stage I, mean age; years } \pm \text { SD } \\
\text { Stage II, } \mathrm{n} \\
\text { Stage II, mean age; years } \pm \text { SD } \\
\text { Stage III, n } \\
\text { Stage III, mean age; years } \pm \text { SD }\end{array}$ & $\begin{array}{c}106(58.9 \%) \\
59.4 \pm 11.0 \\
68(33.0 \%) \\
59.7 \pm 12 \cdot 6 \\
34(33.7 \%) \\
66.9 \pm 6.4\end{array}$ & $\begin{array}{c}74(41.1 \%) \\
59.8 \pm 10.3 \\
138(67.0 \%) \\
60.1 \pm 10.5 \\
67(66.3 \%) \\
60.1 \pm 8.9\end{array}$ & $\begin{array}{l}0.82 \\
0.80 \\
<0.001\end{array}$ \\
\hline RT: Radiotherapy. & & & \\
\hline
\end{tabular}

Table 1.

Patient characteristics $(\mathrm{N}=664)$
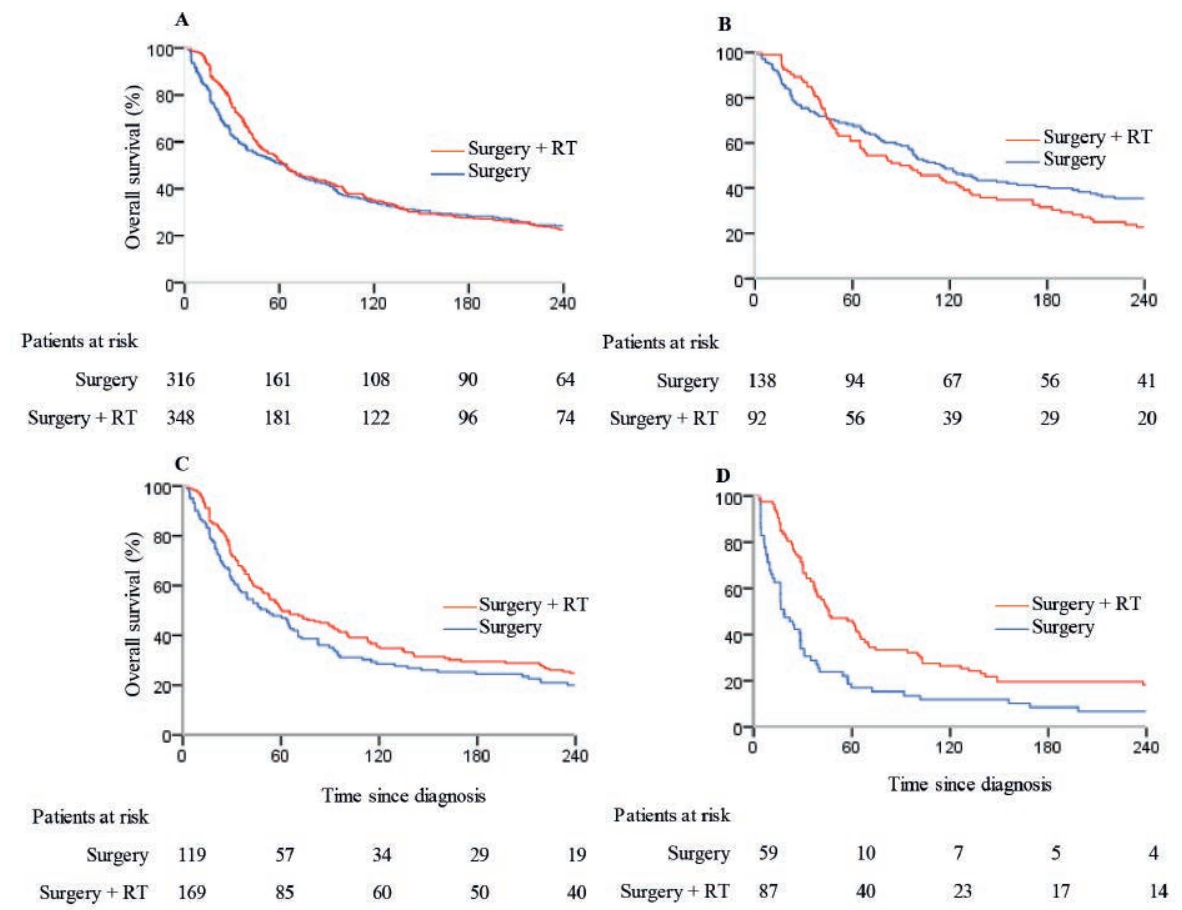

Fig. 1. Kaplan-Meier survival curves for the total study population. A All tumor stages, B tumor stage I, C tumor stage II, and D tumor stage III. RT = radiotherapy.

been treated with RT. In this subgroup the distribution of tumor stage was similar to the whole population, with most patients having stage II disease $(n=206,42.3 \%)$. Differences in age distribution were found only in patients with stage III breast cancer ( 66.9 vs. 60.1 years; $\mathrm{p}<0.001)$.

\section{Overall Survival}

Univariate analysis revealed that young age, more recent year of diagnosis, and early tumor stage were the strongest predictors for increased OS rates, whereas RT had no discernible effect. No significant difference between the survival rates $(\mathrm{p}=0.482)$ was seen for the overall population (fig. $1 \mathrm{~A}$ ). However, subgroup analyses for tumor stage revealed a positive correlation of RT with OS (table 2). This result was statis- tically significant for patients with stage III breast cancer ( $p<0.001)$, with 10 -year survival rates of $26.4 \%$ for patients with RT versus $11.9 \%$ without RT (fig. 1 D). The 20 -year survival rates were higher in patients receiving RT (18.4\%) as compared to patients without RT $(6.8 \%)$. For patients with stage II breast cancer, a similar trend was observed, without reaching the level of statistical significance (10-year OS: $\mathrm{p}=0.102$, 20-year OS: $\mathrm{p}=0.127$; fig. $1 \mathrm{C}$ ). Interestingly, in patients with stage I breast cancers surgery alone led to higher 10 -year (48.6 vs. $42.4 \%$ ) and 20 -year (35.5 vs. $22.8 \%$ ) OS rates as compared to surgery plus RT, although this difference was not statistically significant ( $p=0.515$; fig. 1 B). Again, these findings were confirmed by the Kaplan-Meier estimates of OS. 
The results obtained from Cox regression analyses are summarized in table 3. Tumor stage, age, and year of diagnosis were significant predictors of OS after 10 and 20 years of follow-up. A significant survival benefit was seen in patients treated with RT after 10 years of follow-up ( $\mathrm{p}=0.031$, hazard ratio $(\mathrm{HR})=0.804,95 \%$ confidence interval $(\mathrm{CI})=0.659$ 0.980). This trend was also seen after 20 years of follow-up but did not reach statistical significance $(\mathrm{p}=0.078)$. Stage III patients treated with post-mastectomy RT had a significant $40-42 \%$ benefit in comparison to patients without RT after 10 years $(\mathrm{p}=0.007, \mathrm{HR}=0.580,95 \% \mathrm{CI}=0.391-0.860)$ and 20 years $(\mathrm{p}=0.008, \mathrm{HR}=0.599,95 \% \mathrm{CI}=0.409-0.877)$, respectively.

In the subgroup of patients $<75$ years of age, RT had a significant impact on the OS rates only in patients with stage III cancer (fig. 2 D, table 2). The 10-year OS rate was

Table 2.

Comparison of survival rates after 10 and 20 years for patients with/ without radiotherapy (Kaplan-MeierAnalysis).

\begin{tabular}{|c|c|c|c|c|c|c|c|c|}
\hline Tumor stage & RT & $\mathrm{n}$ & Deaths, $\mathrm{n}$ & $\begin{array}{l}10 \text {-year } \\
\text { OS-rate }\end{array}$ & $\mathrm{p}$ value & Deaths, $\mathrm{n}$ & $\begin{array}{l}20 \text {-year } \\
\text { OS-rate }\end{array}$ & $\mathrm{p}$ value \\
\hline \multicolumn{9}{|c|}{ Total study population $(\mathrm{N}=664)$} \\
\hline I & $\begin{array}{l}\text { no } \\
\text { yes }\end{array}$ & $\begin{array}{r}138 \\
92\end{array}$ & $\begin{array}{l}71 \\
53\end{array}$ & $\begin{array}{l}48.6 \% \\
42.4 \%\end{array}$ & 0.515 & $\begin{array}{l}89 \\
71\end{array}$ & $\begin{array}{l}35.5 \% \\
22.8 \%\end{array}$ & 0.140 \\
\hline II & $\begin{array}{l}\text { no } \\
\text { yes }\end{array}$ & $\begin{array}{l}119 \\
169\end{array}$ & $\begin{array}{r}85 \\
109\end{array}$ & $\begin{array}{l}28.6 \% \\
35.5 \%\end{array}$ & 0.102 & $\begin{array}{r}95 \\
127\end{array}$ & $\begin{array}{l}20.2 \% \\
24.9 \%\end{array}$ & 0.127 \\
\hline III & $\begin{array}{l}\text { no } \\
\text { yes }\end{array}$ & $\begin{array}{l}59 \\
87\end{array}$ & $\begin{array}{l}52 \\
64\end{array}$ & $\begin{array}{l}11.9 \% \\
26 \cdot 4 \%\end{array}$ & $<0.001$ & $\begin{array}{l}55 \\
71\end{array}$ & $\begin{array}{r}6.8 \% \\
18.4 \%\end{array}$ & $<0.001$ \\
\hline Total & $\begin{array}{l}\text { no } \\
\text { yes }\end{array}$ & $\begin{array}{l}316 \\
348\end{array}$ & $\begin{array}{l}208 \\
226\end{array}$ & $\begin{array}{l}34.2 \% \\
35.1 \%\end{array}$ & 0.239 & $\begin{array}{l}239 \\
269\end{array}$ & $\begin{array}{l}24.4 \% \\
22.7 \%\end{array}$ & 0.482 \\
\hline \multicolumn{9}{|c|}{ Subpopulation, $<75$ years $(\mathrm{n}=487)$} \\
\hline I & $\begin{array}{l}\text { no } \\
\text { yes }\end{array}$ & $\begin{array}{r}106 \\
74\end{array}$ & $\begin{array}{l}44 \\
37\end{array}$ & $\begin{array}{l}58.5 \% \\
50.0 \%\end{array}$ & 0.207 & $\begin{array}{l}61 \\
55\end{array}$ & $\begin{array}{l}42.5 \% \\
25.7 \%\end{array}$ & 0.028 \\
\hline II & $\begin{array}{l}\text { no } \\
\text { yes }\end{array}$ & $\begin{array}{r}68 \\
138\end{array}$ & $\begin{array}{l}38 \\
87\end{array}$ & $\begin{array}{l}44.1 \% \\
37.0 \%\end{array}$ & 0.376 & $\begin{array}{r}48 \\
101\end{array}$ & $\begin{array}{l}29.4 \% \\
26.8 \%\end{array}$ & 0.585 \\
\hline III & $\begin{array}{l}\text { no } \\
\text { yes }\end{array}$ & $\begin{array}{l}34 \\
67\end{array}$ & $\begin{array}{l}30 \\
46\end{array}$ & $\begin{array}{l}11.8 \% \\
31.3 \%\end{array}$ & $<0.001$ & $\begin{array}{l}33 \\
52\end{array}$ & $\begin{array}{r}2.9 \% \\
22.4 \%\end{array}$ & $<0.001$ \\
\hline Total & $\begin{array}{l}\text { no } \\
\text { yes }\end{array}$ & $\begin{array}{l}208 \\
279\end{array}$ & $\begin{array}{l}112 \\
170\end{array}$ & $\begin{array}{l}46.2 \% \\
39.1 \%\end{array}$ & 0.191 & $\begin{array}{l}142 \\
208\end{array}$ & $\begin{array}{l}31.7 \% \\
25.5 \%\end{array}$ & 0.166 \\
\hline
\end{tabular}

Table 3. Comparison of hazard ratios by Cox regression analysis

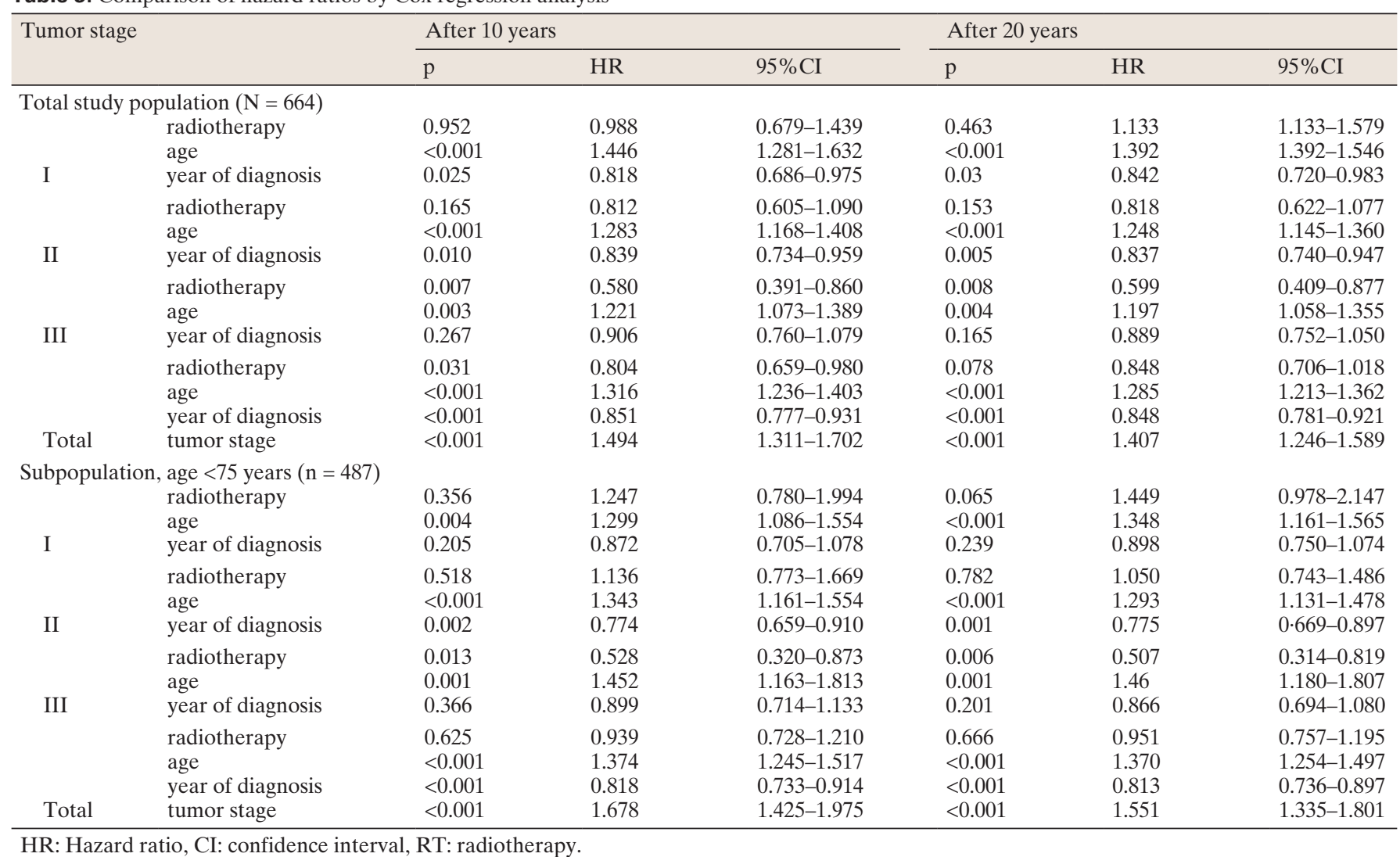



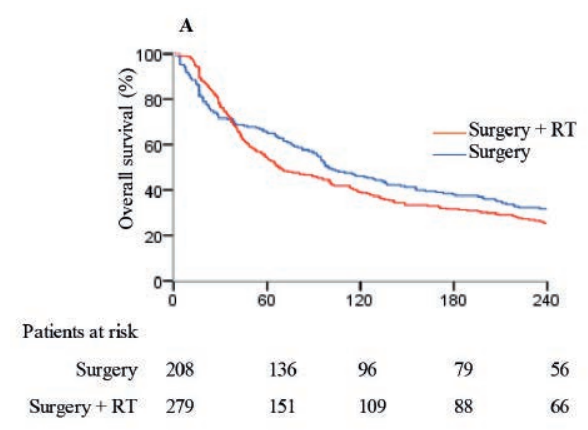

C

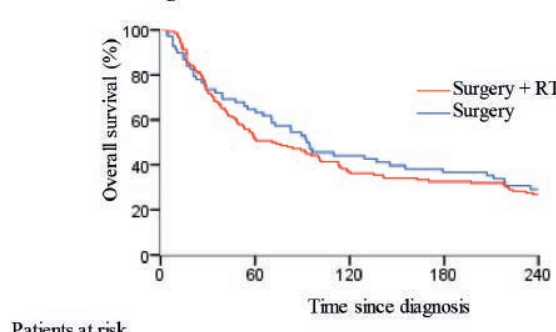

Patients at risk

$\begin{array}{llllll}\text { Surgery } & 68 & 44 & 30 & 25 & 17\end{array}$

$\begin{array}{llllll}\text { Surgery }+ \text { RT } & 138 & 72 & 51 & 45 & 35\end{array}$
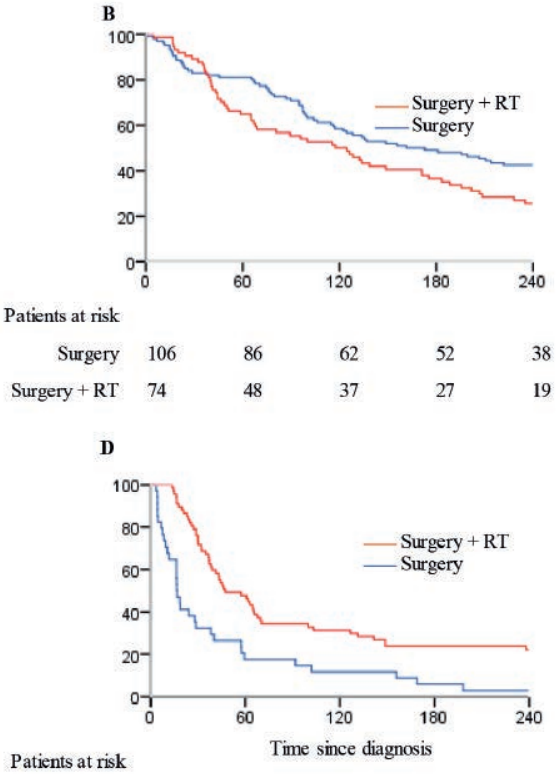

Patients at risk

Surgery 34

Surgery + RT $\begin{array}{llll}6 & 4 & 2 & 1 \\ 32 & 21 & 16 & 13\end{array}$
Fig. 2. Kaplan-Meier survival curves for the subpopulation $<75$ years of age. A All tumor stages, B tumor stage I, C tumor stage II, and $\mathbf{D}$ tumor stage III. RT = radiotherapy.
$11.8 \%$ without RT, increasing to $31.3 \%$ for patients with RT $(\mathrm{p}<0.001)$. This difference was even more pronounced after 20 years, with only $2.9 \%$ of the patients surviving without RT and $22.4 \%$ survivors with RT $(\mathrm{p}<0.001)$. Again, the reverse trend was seen in stage I breast cancer patients: $58.5 \%$ of the patients without RT survived for 10 years, but only $50.0 \%$ of the patients were alive after having received RT (fig. 2 B). This difference was not statistically significant $(\mathrm{p}=0.207)$. However, it reached the level of statistical significance for 20 -year OS (42.5 vs. $25.7 \%$; $\mathrm{p}=0.028$ ).

The Cox regression analyses of patients $<75$ years of age did not show any significant effect of RT if all stages were considered (table 3). Analysis by stage however revealed an increased mortality risk for patients with stage I breast cancer treated with surgery plus RT both after 10 and 20 years $(\mathrm{HR}=$ $1.247(24.7 \%)$ and 1.449 (44.9\%), respectively) as compared to surgery alone. The significance level was not reached after an observation period of 20 years $(\mathrm{p}=0.062)$. In contrast, RT resulted in a $48 \%$ decrease in mortality risk in men with stage III breast cancer after 10 years of follow-up $(\mathrm{HR}=0.528$, $\mathrm{p}=0.013)$ and $49.3 \%$ after 20 years $(\mathrm{HR}=0.507, \mathrm{p}=0.006)$.

\section{Discussion}

To our knowledge, this is the largest retrospective study on male breast cancer patients focusing on the role of adjuvant RT with a median follow-up of 26.2 years $(314 \pm 71.5$ months SD). We analyzed 664 participants in the former East Germany population-based cancer registry with stage I-III breast cancer. Since the frequency of co-morbidity that may influence the clinical decision regarding adjuvant RT increases with age, younger patients were more likely to receive adjuvant $\mathrm{RT}$ as compared to older men. In order to minimize a possible influence of advanced age and comorbidities on the effect of post-surgical RT and OS, we performed a separate analysis on a subgroup of 487 patients $<75$ years old at time of diagnosis. Patients were diagnosed and treated between 1970 and 1989 and received no systemic adjuvant therapy. Therefore, an assumed beneficial effect of systemic treatment does not interfere with OS, providing the possibility to assess the role of RT alone in male breast cancer.

The present analysis reveals different benefits for RT depending on tumor stage. A significant benefit for RT could be demonstrated only in patients with stage III breast cancer with $16.8 \%$ survivors in the RT group versus only $8.6 \%$ in patients without RT after 20 years of follow-up. RT after surgery was an independent positive predictor for survival rates in these patients. Patients with stage II breast cancer also seemed to benefit from RT, but this effect was statistically not significant. In contrast, RT in patients with stage I breast cancer seemed to decrease OS after 20 years of followup in the total population. This difference was age-dependent and reached significance if patients younger than 75 years were analyzed separately. Our results are in accordance with the data from large prospective studies on female patients $[16,17]$. Studies on men with breast cancer are limited due to the small number of patients worldwide and the retrospective approach [18]. Most of the published material predominantly focuses on the effect of RT on relapse-free survival rates as opposed to OS rates, and these studies reveal contradictory results [8]. There are only a few studies investigating the question whether there is an influence of RT on OS [18]. Based on our observations, we can conclude that male patients with 
stage III cancer had a clear benefit from post-mastectomy RT, comparable to the published results for female patients [14].

The increased mortality of patients with stage I breast cancer might be due to toxic effects of RT such as cardiotoxicity, pulmonary toxicity, secondary pulmonary and/or esophageal cancers, and could have been limited to the specific type of RT carried out 30 years ago and earlier (i.e. megavoltage irradiation using Cobalt-60 $\gamma$-radiation) [19-21]. The facts that the benefit of RT in the whole population was limited to the first 10 years of follow-up, and some of the RT-associated toxicity occurs late, may explain why the beneficial RT effect disappears after a longer follow-up time. We have to assume that at the time of the primary diagnosis the calibration of radiation dosages was less precise than today. These facts may explain the poor performance of RT in early-stage tumors for our patient cohort [19].

The biggest limitation of the present study is its retrospective character, together with the fact that data about tumor location, TNM tumor classifications, and co-morbidities were missing. Despite these points, this study represents the largest study performed on male breast cancer patients focusing exclusively on adjuvant RT and OS. Additionally, the observation time of 314 months is the longest documented as of yet.

Based on the present data, the benefit of post-mastectomy RT in the early stage of male breast cancer, especially stage I, should be questioned. Our data shows that RT has a detrimental effect on stage I male breast cancer patients, while confirming the significant benefit for male patients with stage III breast cancer. In stage II male breast cancer, there may be patients who do not benefit from postoperative RT, but further analyses including modern RT techniques are needed to elucidate this therapeutic indication.

\section{Disclosure Statement}

The authors declare no conflict of interest.

\section{References}

1 Fentiman IS, Fourquet A, Hortobagyi GN: Male breast cancer. Lancet 2006:367:595-604.

2 Giordano SH, Cohen DS, Buzdar AU, Perkins G, Hortobagyi GN: Breast carcinoma in men: a population-based study. Cancer 2004;101:51-75.

$\checkmark 3$ Crichlow RW: Carcinoma of the male breast. Surg Gynecol Obstet 1972;134:1011-1019.

4 Sasco AJ, Lowenfels AB, Pasker-de Jong P: Review of article: epidemiology of male breast cancer. A meta-analysis of published case-control studies and discussion of selected aetiological factors. Int J Cancer 1993;53:538-549.

$\checkmark 5$ Thomas DB, Jimenez LM, McTiernan A, et al.: Breast cancer risk in men: risk factors with hormonal implications. Am J Epidemiol 1992;135:734 748.

6 Agrawal A, Ayantunde AA, Rampaul R, Robertson JF: Male breast cancer: a review of clinical management. Breast Cancer Res Treat 2007;103:11-21.

7 Contractor KB, Kaur K, Rodrigues GS, Kulkarni DM, Singhal H: Male breast cancer: is the scenario changing. World J Surg Oncol 2008; 6:58.

8 Giordano SH: A review of the diagnosis and management of male breast cancer. Oncologist 2005;10:471-479.

-9 Schuchardt U, Seegenschmiedt MH, Kirschner MJ, Renner H, Sauer R: Adjuvant radiotherapy for breast carcinoma in men: a 20-year clinical experience. Am J Clin Oncol 1996;19:330-336.

10 MacDonald G, Paltiel C, Olivotto IA, Tyldesley S: A comparative analysis of radiotherapy use and patient outcome in males and females with breast cancer. Ann Oncol 2005;16:1442-1448.

11 Miao H, Verkooijen HM, Chia KS, et al.: Incidence and outcome of male breast cancer: an international population-based study. J Clin Oncol 2011;29: 4381-4386.

12 Rowell NP: Radiotherapy to the chest wall following mastectomy for node-negative breast cancer: a systematic review. Radiother Oncol 2009;91:23-32.

13 Vetto J, Jun SY, Paduch D, Eppich H, Shih R: Stages at presentation, prognostic factors, and outcome of breast cancer in males. Am J Surg 1999; 178:436.

14 Robison R, Montague ED: Treatment results in males with breast cancer. Cancer 1982;49:403-406.

15 Stang A, Stabenow R, Stemaier C, Eisinger B, Bischof-Hammes E, Jöckel KH: Unexplained inversion of the incidence ratio of colon and rectal cancer among men in East Germany. A time trend analysis including 147,790 cases. Eur J Epidemiol 2007;22:245-255.

16 Danish Breast Cancer Cooperative Group, Nielsen HM, Overgaard M, Grau C, Jensen AR, Overgaard J: Study of failure pattern among highrisk breast cancer patients with or without post- mastectomy radiotherapy in addition to adjuvant systemic therapy: long-term results from the Danish Breast Cancer Cooperative Group DBCG $82 \mathrm{~b}$ and $\mathrm{c}$ randomized studies. J Clin Oncol 2006; 24:2258-2275.

17 Ragaz J, Olivotto IA, Spinelli JJ, et al.: Locoregional radiation therapy in patients with highrisk breast cancer receiving adjuvant chemotherapy: 20-year result of the British Columbia randomized trial. J Natl Cancer Inst 2005;97:116-126.

18 Chakravarthy A, Kim CR: Post-mastectomy radiation in male breast cancer. Radiother Oncol 2002; 65:99-103.

19 No authors listed: Favourable and unfavourable effects on long-term survival of radiotherapy for early breast cancer: an overview of the randomised trials. Early Breast Cancer Trialists' Collaborative Group. Lancet 2000;355:1757-1770.

20 Højris I, Overgaard M, Christensen JJ, Overgaard J: Morbidity and mortality of ischaemic heart disease in high-risk breast-cancer patients after adjuvant postmastectomy systemic treatment with or without radiotherapy: analysis of DBGC $82 \mathrm{~b}$ and $82 \mathrm{c}$ randomised trials. Radiotherapy Committee of the Danish Breast Cancer Cooperative Group. Lancet 1999;354:1425-1430.

21 Hurkmans CW, Borger JH, Bos LJ, et al.: Cardiac and lung complication probabilities after breast cancer irradiation. Radiother Oncol 2000;55:145-151. 